\title{
Transnational Climate Governance Networks and Domestic Regulatory Action
}

\section{Xun Cao \& Hugh Ward}

To cite this article: Xun Cao \& Hugh Ward (2016): Transnational Climate Governance Networks and Domestic Regulatory Action, International Interactions, DOI: 10.1080/03050629.2016.1220162

To link to this article: http://dx.doi.org/10.1080/03050629.2016.1220162

View supplementary material $₫$

Accepted author version posted online: 05
Aug 2016.
Published online: 05 Aug 2016.

Submit your article to this journal $\pi$

Џll Article views: 8

a

View related articles ¿

View Crossmark data $₫$ 


\section{TRANSNATIONAL CLIMATE GOVERNANCE NETWORKS AND DOMESTIC REGULATORY ACTION}

Xun Cao

Department of Political Science

Penn State University

Hugh Ward

Department of Government

University of Essex

Transnational climate governance (TCG) creates networks between countries as governments and other organizations enter joint arrangements to further their interests. We argue that actors build TCG, rather than focusing on promoting change at the domestic level, when this is a more efficient way of using their limited resources than lobbying to increase the level of domestic regulation. Based on standard micro-economic theory, we show that actors will respond to higher existing levels of domestic regulation by participating more in TCG, because the existence of such domestic legislation frees up resources for them to use in other ways, including activities at the transnational level. We carry out an empirical test based on the strength of the network ties between countries formed by TCG. Results support our main hypothesis on the positive relationship between a country's level of domestic policy output and its participation in TCGs, suggesting that national policies and TCGs are more complements than substitutes as instruments to address global climate change. 
Key words: transnational climate governance; domestic environmental policies; networks; latent space model.

Correspondence address to Xun Cao: Department of Political Science, Penn State University

206 Pond Lab University Park, PA 16802, Phone: 814-865-8749

Transnational climate governance (TCG) creates networks between countries as governments and other organizations enter joint arrangements to further their interests. Some of these arrangements are sponsored by, or strongly steered by, the actions of states or international organizations. In this article, we focus on other arrangements - specifically those that are led by corporations, NGOs or sub-national units of government such as cities (Bulkeley, Andonova, Betsill, Hale, Hoffmann, Newell, Paterson, Roger, and Vandeveer 2014; Hale and Roger 2014). We call these transnational climate governance (TCG) (Andonova, Betsill and Bulkeley 2007; Green 2014; Hale and Rogers 2014). Why do such actors use their resources to build TCG rather than focussing on promoting change at the domestic level? ${ }^{1}$ Our argument is that they do so when this is a more efficient way of using their limited resources than lobbying for action at the national level to increase domestic regulation. We highlight that the more legislative action there has been at domestic level, the greater the participation of actors in TCG. This is because if they can bank on the domestic legislative environment being favourable to their interest in climate change governance, organizations are less resource-constrained in relation to participating in TCG.

\footnotetext{
${ }^{1}$ Herein for brevity we drop the "sub/non state" prefix.
} 
Currently we lack a firm understanding of the domestic conditions that influence participation in transnational ties. Andonova (2014) provides a number of answers to another important question: what factors condition TCG arrangements where states do play an important leadership or conditioning role. Her specific focus is on arrangements arising from the Johannesburg Earth Summit, not all of which specifically concern climate change. Hale and Roger (2014) focus on transnational governance of climate change, but specifically on arrangements led by states (comprising around $30 \%$ of the total). The pioneering study of domestic influences using large-n statistical methods is that of Andonova, Hale and Roger (2015). They suggest that when governments hold pro-environmental views, this facilitates organizations' involvement in TCG. They find some evidence that pro-environmental policies promote organizations' involvement and quite strong evidence that state capacity does so. We build on this study by providing a strong theoretical rationale for the idea that a favourable domestic regulatory environment encourages participation.

In addition to introducing a new measure for domestic climate change policy capturing the number of relevant domestic legislative instruments, we make three core contributions. First we use a rational agent perspective to develop specific hypotheses about domestic influences on action. This approach has proven extremely useful, alongside others, in constructing descriptive narratives about TCG (Bulkeley et al. 2014; Schäferhoff, Campe, and Kaan 2009). For instance, Green (2014) uses a rational choice supply/demand model to develop hypotheses about why states delegate authority to private actors in some instances while private organizations develop 'entrepreneurial authority' in others. Our argument complements Green's. First we add that domestic legislative action can, in some circumstances, provide similar benefits to international 
cooperation between states - and to private authority. Second we stress that organizations face trade-offs in pursuing goals associated with climate governance because they have finite resources.

Our second contribution is to bring a network perspective to bear on the study of TCG. Although TCG has been widely cast in the literature, and even defined as, a network phenomenon (Andonova, Betsill and Bulkeley 2009), surprisingly little use has been made of concepts from social network analysis and associated methods that are now becoming widely used in political science (Hafner-Burton, Kahler and Montgomery 2009; Ward, Stovel, and Sacks 2011), and are starting to be used in the global environmental politics literature (Ward 2006; Cao and Prakash 2010 and 2102; Kalbhenn 2011, Spilker 2012; Ward and Cao 2012; Schaffer and Bernauer 2014; Grundig and Ward 2015; Böhmelt and Vollenweider 2015). We add to the small number of studies in the recent literature using formal social network analysis. Lee and van de Meene (2012) study the directed network formed when one city involved in the C40Cities TCG program learns off another affiliated city. Green (2013) uses social network analysis to examine links when one greenhouse gas emissions standard recognizes another, enabling her to analyse which standards are central to this network. Widerberg (2014) moves beyond enumerating organizations involved in the climate regime complex (Keohane and Victor 2011; Abbott 2012) to map links between them, using affiliation to institutions and hyperlinks on organizations' websites to other organizations. There is growing recognition in social network theory that it is often inappropriate to treat network ties as givens when they actually emerge from the strategic choices of agents (Jackson 2008:257-319). By considering the domestic factors that influence networks built by rational actors, we start to endogenise the network. 
Our third contribution is to recognize that, in testing models of how networks develop, it is important to recognize that observations are not independent and to use appropriate econometric methods to deal with this. Looking at network ties helps us to answer our question about the effects of domestic legislation on organizations' participation in transnational arrangements. However, care needs to be exercised in making statistical inferences. Several organizations in states $j$ and $k$ may be involved in negotiating an arrangement. If negotiations are successful, to use the language of social network theory (Wasserman and Faust 1994), a co-affiliation link is created between $j$ and $k$. If, as will frequently be true empirically, organizations in some other state, $i$, are involved, network links are also created between $j$ and $i$ and between $k$ and $i$. This is a 'friend of your friend is likely to be your friend' effect. Notice that this implies that the probability of a tie between $j$ and $k$ is unlikely to be independent of the occurrence of other links in the network involving $j, k$ and third states. If such interdependencies are not taken into account we are liable to get biased estimates of the effects of domestic covariates, as detailed in the section on latent-space models (Hoff, Raftery and Handcock 2002).

\section{TCG as a Network Phenomenon}

When organizations in countries $i$ and $j$ are involved in a TCG arrangement, they strengthen the network tie between the two countries. Our paper is different from others in this special issue in that our empirical focus is on explaining the strength of such network ties, based on our model of the trade-off that individual organizations face. The network is only strengthened if an actor in country $i$ and an actor in country $j$ are willing to participate in an arrangement. Thus we argue that the overall strength of the network tie (allowing for multiple organizations on each side) 
increases with the degree of development of legislation in the country that has the lowest level of domestic legislative action. This is a 'weakest link' argument (Hirshleifer 1983); it is the incentives of the actors most loath to participate that govern connections. ${ }^{2}$ Thus we adopt a rational agent perspective but, in line with a systemic approach to TCG (Bulkeley et. al. 2014), we emphasise that ties between countries are an emergent consequence of rational action of individual actors.

At first sight to focus on network ties between countries rather than network ties between particular actors may seem a rather odd perspective, albeit that our argument derives from a theory of the domestic influences on organizations. However, transnational ties do more than link the agents explicitly involved in them. They create ties between countries, and second-order links between agents within them, along which information and normative influences flow. Although we do not deal in depth with information and influence flows in this paper, their potential importance helps to justify our research question. Even relatively functionally diffuse ties of this sort may play a role in promoting sustainability (Ward 2006). As conduits for information flows between societies they may also lead to policy diffusion (Simmons, Dobbin,

\footnotetext{
${ }^{2}$ Hirshleifer's (1983) is an argument about public goods provision. Effective transnational climate governance is a public good, but it production often also co-generates private good benefits for participants, for example, profits from participation in markets for carbon offsets. For applications of weakest link arguments to democratic peace and international conflict, see Dixon (1993) and Oneal and Russett (1997).
} 
and Garrett 2006) and even to subsequent convergence of environmental policy between societies (Holzinger, Knill and Sommerer 2008).

In this regard it is important to note that one characteristic form of TCG involves information exchange. Indeed Bulkeley et al. (2014) calculate that $90 \%$ of the sixty TCG arrangements they look at perform this function; and, furthermore, nearly the same proportion function to build capacity. ${ }^{3}$ For instance, an important focus for TCG has been networks between cities (Bulkeley 2010; Lee and van de Meene 2012). Between 2008 and 2010 the World Economic Forum's SlimCity programme allowed city mayors and businesses to exchange information about using energy efficiently at city level (World Economic Forum 2009). The mayor of San Francisco and the Governor of Rio de Janeiro were both involved in this initiative. Each may have learned from the other about how to use energy efficiently. But they were also enmeshed in regional and national networks at domestic level. For instance San Francisco is also a member of the US Mayor's Climate Protection Agreement. Information mayors learned through SlimCity can be passed on through these domestic networks, even though many actors in these domestic networks are not directly involved in Slimcity. Moreover what mayors know and can transmit directly to other actors involved in SlimCity is partly a function of the information they receive through domestic networks. Also when cities network internationally, they create opportunities for their

\footnotetext{
${ }^{3}$ As shown in the introduction to this special issue Figure 2, the proportion of arrangements mapped in the data we use providing information and networking services fell from around $75 \%$ in 1990 to around 30\% in 2010 (Roger, Hale and Andonova nd.). However, the proportion is still substantial.
} 
mayors and officers to act as policy and norm entrepreneurs (Bulkeley 2010). Cities learn from each other directly by participating in networks (Lee and van de Meene 2012). In addition, cities' involvement in TCG generates second-order links between business communities and citizens' groups in cities, even if they are not directly linked; and it creates second-order links with cities not directly involved in TCG.

Domestic lobbying activity can be costly in terms of time and money spent gathering information, maintaining personal ties and making contributions to politicians' election funds. Participation in TCG is not cost-free, either. Information exchange requires time and effort to package information for others and to assimilate information the organization receives. Because they can informationally benefit some actors which do not bear the costs of TCG arrangements, the links we emphasise have the public-goods property of non-excludability. Nevertheless, it may be rational for organizations to use resources in building them because only participants get access to certain benefits, such as direct or enhanced access to information.

According to Bulkeley et al (2014) some $50 \%$ of the TCG arrangements they looked at functioned to set standards. Like information exchange, adhering to a standard also has opportunity costs, because standards preclude potentially profitable activities. ${ }^{4}$ Standard-setting

\footnotetext{
${ }^{4}$ Additional costs for involvement in transnational networks involve the allocation of administrative staff and resource for participation, meeting commitments, and/or resources toward increasing capacity for action.
} 
also creates links between countries. ${ }^{5}$ As Potoski and Prakash (2005) argue, corporations adhering to a credible environmental standard enjoy reputational benefits with customers, suppliers and government regulators that they can only get by joining the 'green club'. If a corporation in country $i$ voluntarily offsets some of its carbon emissions against schemes accredited by, say, The Gold Standard, this can have a network externality effect on corporations in country $j$, increasing the value they place on offsetting. There is what Ostrom (2012) calls a nested externality: in this case, action at trans-governmental scale creates an externality linking national markets.

\section{Theory}

Focussing on transnational ties enables us to ask whether organizations develop transnational arrangements partly because this is a rational course of action for them given the degree of development of national policy in the country where they are based, and given the transaction costs associated with forging links with other organizations. It is a commonplace that corporations make rational use of resources so as to achieve desired ends; and the same assumption can be argued to be plausible for NGOs and sub-national governments. Resource mobilization theories of social movements suggest that NGOs have endemic problems with mobilizing their latent support, and must use resources wisely to maintain support and flows of resources from members (Edwards and McCarthy 2004). An important motive for local

\footnotetext{
${ }^{5}$ In 2010 around $44 \%$ of TCG arrangements concerned standard setting and commitments (Roger, Hale and Andonova 2017).
} 
politicians is to win elections by making rational choices over the policies and taxes they offer (Besley and Case 1995). We assume organizations make rational decisions about forming transnational ties.

The literature suggests that organizations pursue a number of purposes through TCG: information sharing; rule setting; provision of collective goods; financial functions; capacity building and implementation (Andonova, Betsill and Bulkeley 2007). Governance arrangements 'purposively steer constituent members to act' (Andonova, Betsill and Bulkeley 2007: 5). Regulation by states through domestic policy can aim to do the same thing, though sometimes through different means. For instance, cities concerned with their carbon emissions could lobby their government to set (binding or non-binding) targets for cities, or they could act to set up a TCG arrangement like C40Cities (Lee and van de Meene 2012) to encourage action through sharing of information. Similarly NGOs and corporations concerned about the low quality of some carbon offsets could have lobbied for state regulation of the domestic market rather than initiating a transnational arrangement. ${ }^{6} \mathrm{We}$ assume that there is usually at least some overlap between what organizations can get through transnational arrangements and what they can get through lobbying to tighten domestic regulation, though we concede that this may not always be the case. This does not commit us to the view that organizations see lobbying and building transnational governance as equally efficient responses. For instance national regulation of carbon offsets might well be viewed as relatively inefficient by domestic interests because the

\footnotetext{
${ }^{6}$ Green (2017) shows that some governments' domestic legislation recognizes private offset standards, often alongside national standards. Again this suggests a degree of substitutability.
} 
standard would only apply to one market. ${ }^{7}$ We allow for organizations' perceptions of relative efficiency via their utility function over national policy and transnational activity.

On the assumption that TCG and domestic regulation are partial substitutes, organizations face a trade-off between them, because they face a resource constraint. Let the utility function of organization $o$ in country j's be

$$
\mathrm{U}\left(\mathrm{p}, \mathrm{t}, \mathrm{p}_{\Sigma}\right)
$$

where $\mathrm{p}$ is the level of national policy, $\mathrm{t}$ is $o$ 's level of transnational activity, and $\mathrm{p}_{\Sigma}$ is the level of policy in the rest of the world outside j. (We simplify notation by dropping subscripts $o$ and j.) Then we assume:

$$
\delta \mathrm{U} / \delta \mathrm{p}>0 ; \delta \mathrm{U} / \delta \mathrm{t}>0 ; \delta \mathrm{U} / \delta \mathrm{p}_{\Sigma}>0 ; \delta^{2} \mathrm{U} / \delta \mathrm{p}^{2}<0 ; \delta^{2} \mathrm{U} / \delta \mathrm{t}^{2}<0 ; \text { and } \delta^{2} \mathrm{U} / \delta \mathrm{p}_{\Sigma}^{2}<0
$$

i.e. $o$ 's utility increases with the level of domestic and international policy and its transnational activity, but marginal utilities are declining.

Because climate change is a global problem that cannot be solved by action at national level in any one country, it can be assumed that all organizations have some concern about what happens in other national jurisdictions. Nevertheless we expect their degree of concern to vary. A mayor may want to share information with mayors in other cities, but if her motives primarily centre on re-election, she may not be particularly concerned with outcomes in cities overseas - unless her

\footnotetext{
${ }^{7}$ Although, if the country was economically powerful enough, it might diffuse through the 'California Effect' whereby foreign corporations comply to gain better access (Vogel 1995).
} 
voters are, too. If she could obtain the same information more easily at domestic level, it might well be rational to do so. On the other hand, the supporters of many environmental NGOs are strongly internationalist in outlook; so their leaders have (or must act as if they have) inherent concern for outcomes overseas. We expect the marginal rate of substitution between domestic policy and transnational action ${ }^{8}$ to vary systematically across different types of organization. Figure 1 shows three of $o$ 's indifference curves for fixed $\mathrm{p}_{\Sigma}$ in $(\mathrm{p}, \mathrm{t})$ space, labelled I1, I2 and I3. The more $o$ cares about transnational action compared to domestic policy the flatter the indifference curve through a particular point.

(Figure 1 here)

Let the level of policy in country $\mathrm{j}$ if $o$ does not lobby be $\mathrm{p}_{\mathrm{e}}$. Suppose that $o$ spends 1 units of resource on lobbying. Then we assume that the level of policy becomes:

$$
\mathrm{p}=\mathrm{p}_{\mathrm{e}}+1 / \pi
$$

where $\pi>0$ represents the costs of lobbying. Pushing policy forward is not costless because $o$ faces resistance from a counter-lobby that could consist of domestic producers of fossil fuels, heavy industrial users of energy, or government departments primarily concerned with competitiveness or (narrowly defined) economic development. The greater the power of the counter lobby, the larger the value of $\pi$. In general there could be strategic interdependence between $o$ and other organizations. We assume that organization $o$ does not expect others to react. This may be reasonable where large numbers of others are involved in an arrangement, so

\footnotetext{
${ }^{8}$ Equal to $(\delta \mathrm{U} / \delta \mathrm{p}) /(\delta \mathrm{U} / \delta \mathrm{t})>0$.
} 
that it is difficult for organizations to carry out a strategic analysis. Following the trend towards using game theory in the recent literature on environmental political economy (e.g. Bechtel and Urpelainen 2014), in the online appendix, a preliminary analysis suggests that our main argument generalizes if there are complementarities, so when $o_{i}$ puts more effort into TCG, the marginal benefit $o_{j}$ gets from investing in TCG increases.

We assume that $o$ cannot affect policy in the rest of the world directly. If it can do so at all, it does so indirectly through its transnational governance activities, for instance by helping to 'boomerang' back global civil society's views on the government of one of its transnational partners (Keck and Sikkink 1998). This is an idealization, because groups can and do affect policy outside their domestic system, even if costs are typically higher. Our central arguments generalise if we relax this assumption, however.

If $o$ expends $t$ units of resource on transnational activity, its involvement is $t / \tau, \tau>0$. One factor affecting the efficiency of such activity is transaction costs with organizations in other jurisdictions, $\tau$. As these go up, we expect $\tau$ to increase.

Organization $o$ faces a resource constraint:

$$
1+\mathrm{t} \leq \mathrm{r}
$$

Using dotted lines figure 1 shows $o$ 's feasibility frontier in $(\mathrm{p}, \mathrm{t})$ space for three different levels of current domestic policy, $\mathrm{p}_{\mathrm{e}}{ }^{\prime}, \mathrm{p}_{\mathrm{e}}$ ", and $\mathrm{p}_{\mathrm{e}}{ }^{\prime \prime}$. Organization $o$ gets $\mathrm{p}_{\mathrm{e}}$ units of public policy even if it expends no resources on lobbying. It can increase the level of public policy up to $\mathrm{p}_{\mathrm{e}}+\mathrm{r} / \pi$ by 
expending all its resources on lobbying. ${ }^{9}$ On the other hand if it expends nothing on lobbing it can afford $r / \tau$ units of transnational activity. The downward sloping portion of the feasibility frontier has slope $-\pi / \tau$. As $p_{e}$ increases the frontier expands outward, as shown.

Organization $o$ has a resource income r. However, this is not its only source. In formal terms $\mathrm{p}_{\mathrm{e}}$ is analogous to a portion of consumer income that must be spent and, moreover, must be spent on one particular good. As o's 'income' (in this sense) goes up, its optimal mix of domestic lobbying and building transnational governance will change. As in standard consumer theory, optima are points of tangency between the feasibility frontier and indifference curves. We make the further assumption that both transnational action and domestic policy are normal goods, with positive income elasticity of demand. Then as $o$ 's 'income' from existing domestic policy goes up, it choses more transnational action, as shown in figure 1: as domestic policy increases from $\mathrm{p}_{\mathrm{e}}$ ' through $\mathrm{p}_{\mathrm{e}}$ " to $\mathrm{p}_{\mathrm{e}}$ "', $o$ 's transnational activity goes up from t' through t", to t"'. Because $o$ has fixed disposable income $\mathrm{r}$, all of which it spends, domestic lobbying goes down from $\left(\mathrm{r}-\mathrm{t}^{\mathrm{\prime}} / \tau\right)$, through $(\mathrm{r}-\mathrm{t} " / \tau)$ to $(\mathrm{r}-\mathrm{t}, " / \tau) \cdot{ }^{10}$

Because this is a critical assumption in our model, it is worth pausing to think about why the feasibility frontier could expand outwards with the current level of domestic policy, $\mathrm{p}_{\mathrm{e}}$. First this

\footnotetext{
${ }^{9}$ As we assume that $o$ cannot affect the level of $\mathrm{p}_{\Sigma}$, it would be irrational to spend resources on lobbying outside its jurisdiction.

${ }^{10}$ Note that $o$ still enjoys a higher level of domestic policy the greater its 'income' (consistent with policy being a normal good) even though it lobbies less.
} 
would be so if domestic legislation can partially substitute for international governance and there is some degree of institutional 'stickiness' in policy. If organizations had continually to defend the status-quo level of regulation, they would be unable to 'bank' on it when deploying their resources elsewhere. However, we think that it is generally the case that it is harder to change the legislative equilibrium than to defend a status-quo policy once it is in place, as theories of punctuated equilibria in policy making suggest (Baumgartner and Jones 1993; Jones and Baumgartner 2005). While there are examples of governments rolling back climate change regulation, we do not think this is common so far.

Moreover domestic legislation may free resources in less obvious ways, too. From the perspective of new institutional economics the transaction costs of investing in a common language, exchange of information, and trust are crucial to explaining the form taken by institutions. Applying this insight to transnational advocacy coalitions, Prakash and Gugerty (2010) argue that they will emerge in areas where there is considerable uncertainty and high costs to learning, so that up-front investment costs are high. Although domestic legislation may not directly substitute for transnational governance, it may reduce transaction costs for organizations under its jurisdiction, for instance by providing a common perceptual frame and a degree of trust at the domestic level between organizations from the country concerned that helps when they get involved in a transnational initiative.

Figure 2 illustrates the effect of changing the marginal rate of substitution, other things equal. As transnational governance becomes more important to the organization, indifference curves becomes flatter (I2 instead of I1) and the organization chooses more transnational activity ( $\mathrm{t}$ " 
instead of t') and less lobbying. For instance, an international NGO might have the flatter curve I2 compared with a local politician more concerned with domestic politics.

(Figure 2 here)

Figure 3 illustrates the effect of increasing the price of domestic lobbying, $\pi$, other things equal. The maximum domestic policy that can be attained falls, and the sloping portion of the budget constraint becomes steeper. The price of domestic lobbying might go up if, for example, the size of the domestic carbon lobby was large, as is the case in the US and Russia. As policy is a normal good, the organization carries out less lobbying, resulting in a lower level of domestic policy. The effect on transnational action is indeterminate: the relative price of lobbying increases, encouraging more transnational activity (the substitution effect); but the increased price of lobbying reduces $o$ 's income, which tends to reduce transnational activity (the income effect); the sum of these effects could be positive or negative. ${ }^{11}$

\section{(Figure 3 here)}

Figure 4 illustrates the effect of decreasing the price of transnational action, $\tau$, other things equal. For instance, such action may be less costly for an NGO already heavily involved at the international level than for a city that has largely operated at the domestic level to date. This time more transnational action is chosen in equilibrium, but the effect on domestic lobbying is also indeterminate.

${ }^{11}$ In figure 3 the income effect predominates and transnational action decreases. 
(Figure 4 here)

In summary, our key theoretical expectations at the organizational level of analysis can be summarized as follows:

I. The greater the level of current national policy output, the more effort $o$ will put into creating transnational ties, other things equal;

II. The greater the priority $o$ puts on transnational payoffs, the more effort it will put into creating transnational ties, other things equal;

III. The lower the transaction costs for dealing outside its national base, the more effort $o$ will put into creating transnational ties, other things equal.

We return to these points in our development of hypotheses.

From the individual organization to the state-dyadic level: weakest links

Now we move from the micro-level of the incentives facing individual transnational agents to the national and dyadic levels at which ties between countries exist. The tie between countries $i$ and $j$ is strengthened when an organization from $i$ and an organization from $j$ both join an arrangement. Thus we focus on the organization with the smaller incentive to join. Note that the patterns of domestic incentives we focus on are common to all organizations in a particular country.

Our dependent variable is the number of transnational links between countries $i$ and $j$ in the transnational governance network, i.e. the number of arrangements that have at least one organization in $i$ and at least one organization in $j$ as a member. To use terminology from 
network theory, we model the value of the edge between $i$ and $j$ in a non-directed graph representing co-affiliation (Wasserman and Faust 1994). In modelling this we use a weakest-link argument.

An arrangement links $i$ and $j$ only if it includes at least one organization from each country. First, a link could be forged when organizations from $i$ and $j$ agree with others to initiate an arrangement. No link is created between $i$ and $j$ if either organisation prefers not to go ahead. ${ }^{12}$ The probability of a potential co-affiliation tie increases as the incentives of the organisation most loath to go ahead in $i$ and $j$ increase. Second, an organization $o$ from $j$, say, may or may not decide to join an existing organization. Again what governs whether a link is forged between $i$ and $j$ is how loath $o$ is the join. In developing testable implications we focus on national-level factors governing this rather than the idiosyncratic ones characterizing particular organizations, which are difficult to capture empirically. Thus:

H1: The value of the transnational link between $i$ and $j$ will increase with the level of development of national policy in the member of the dyad with the least-developed national policy to combat climate change (in line with point $i$ on the summary of the previous section).

A strong domestic environmental constituency correlates positively and significantly with national participation in public-private partnerships for sustainability (Andonova 2014). We assume that environmental NGOs have a strong support constituency for international action;

\footnotetext{
${ }^{12}$ Negotiations in relation to the same arrangement could continue between other dyads, but even if they succeed, no link is created between $\mathrm{o}_{\mathrm{i}}$ and $\mathrm{o}_{\mathrm{j}}$.
} 
hence they place considerable emphasis on transnational payoffs. In addition pressure from environmental NGOs may increase the incentives of other organizations like cities to become involved in transnational arrangement (Dolšak and Prakash nd). Then:

H2: The value of the transnational link between $i$ and $j$ should increase with the number of environmental NGOs in the member of the dyad with the lowest number of environmental NGOs (in line with point ii above).

Although, consistent with the emphasis of this special issue, our main focus is on domestic politics, international factors enter via transaction costs. These should go up with the geographical distance between $i$ and $j$. We also assume that transaction costs for negotiating transnational arrangements are lowered by trade ties between $i$ and $j$. In line with classic liberal arguments, Dorussen and Ward 2010 find that conflict between countries falls with both direct and indirect ties in the trade network, the importance of indirect ties, especially, suggesting that this partly relates to information flows. If organisations know more about each other's societies and values, it should be easier to reach agreement. So (in line with point iii) above):

H3: The value of the transnational link between $i$ and $j$ should decrease with the distance between them and;

H4: The value of the transnational link between $i$ and $j$ should increase with dyadic trade between $i$ and $j$. 


\section{Data}

Shared TCGs: Our dependent variable is the shared number of TCGs between two countries during the 1990 and 2013 period. We use data discussed in Roger, Hale and Andonova (nd.). We exclude 'orchestrated' transnational climate governance arrangements where a state or IGO has played an important role. The data gives starting dates and ending dates for arrangements, from 1990 onwards. Most came into operation after 2000. All but about 10\% were still extant in 2013. However, the data set does not provide the time a country joined and/or left a TCG, but only whether it was part of TCG during the period 1990 onwards. As is impossible for us to create yearly cross-sections, we treat the data as a single cross-section. We then use the country-level data to calculate a co-affiliation network where the value of the edge between country $i$ and country $j$ is the number of arrangements which came into operation between 1990 and 2013 having one or more member organizations in both $i$ and $j$.

Figure 5 is a visual representation of the network. The closer countries are in the figure the more ties there are between them; and the larger the font size used for a county's acronym, the more arrangements it has entered in total. ${ }^{13}$ The figure brings out the fact that ties are predominantly between rich developed countries themselves, and between rich developed countries and newly emerging economies like China, India, and Brazil. Moreover, there is clustering such as a large European bloc in the lower right, a Scandinavian bloc to the right of them, a US, Canada, and

\footnotetext{
${ }^{13}$ For clarity, we do not draw edges for values $\leq 5$. Many countries are not involved in global TCG networks.
} 
Australia bloc, and a China, India, Brazil, Mexico, South Africa block. Note that there are 135 countries in this figure, but only 70 of them are included in the latent space model analysis because of missing data on the right-hand side variables. ${ }^{14}$ Table A5 of the online appendix lists the countries, their acronyms and whether they are included in the empirical analysis.

(Figure 5 about here)

Key Explanatory Variables: Four salient factors affect the chances of a link existing between two countries via TCG: a) the shared number of TCGs between two countries should increase with the level of development of national policy, the number of domestic environmental NGOs, and the density of trade between the two countries; b) it should decrease with the distance between the two countries. Following the discussion above, we use the weakest link approach to create the dyadic version of these variables.

Our measure of national policy is drawn from the IEA/IRENA global renewable energy policies and measures database. ${ }^{15}$ This gives information on national policies under the following broad headings: economic instruments; information and education; policy support; regulatory instruments; research and development; and voluntary approaches. The date each policy came into force and ended is given. Our base measure of national policy, domestic legislation, is the number of listed policies and measures that were in force at some time during the period 1990-

\footnotetext{
${ }^{14}$ The variable most responsible for this is the domestic legislation variable: only about 100 countries are included in the data set.

${ }^{15}$ See http://www.iea.org/policiesandmeasures/renewableenergy/.
} 
2013. For dyad $i, j$ we take the lower of the national values. Other empirical studies of TCG have used a general Environmental Performance Index (Andonova, Hale and Roger 2014; Hsueh nd.) or particulate air pollution (Andonova, Hale and Roger 2014) as proxies for national policy on climate change. Our measure is more closely related to climate change, although it does not directly capture carbon taxes (Ward and Cao 2012) and energy conservation policy. ${ }^{16}$

We measure the number of environmental NGOs (green NGOs) by the average number of environmental NGOs registered in a country with the International Union for Conservation of Nature (IUCN) between 1990 and 2006 (Bernauer et al. 2013). We also take the lower of the national values. To capture general trade network ties between countries, we started with Gleditsch's (2002) trade data, taking the average level of bilateral trade measured in real terms for the period 1990 to 2000 . Because of missing values in the bilateral trade data, we then estimated a gravity model of trade, calibrated using Gleditsch's data, and used this to create a

\footnotetext{
${ }^{16}$ Adopted policies could be numerous but not particularly strong. One reason is that energy intensive groups might be able to block a strong policy by agreeing to a number of less significant policies. Ideally one should code the strength of each domestic policy; but this is hard to operationalize across countries. A country's environmental treaty commitment often strongly correlates with its domestic efforts (Cao and Prakash 2012); green taxes are can be considered a strong policy because they often affect energy intensive sectors directly. Our domestic policy variable gains some credibility from correlating with the total number environmental treaties variable at 0.49 and with per capital green taxes variable at 0.24 .
} 
proxy for total dyadic trade, trade proxy. ${ }^{17}$ For the effects of distance in geography, we use Gleditsch and Ward's (2001) minimum distance data (distance). This records the shortest distance between points on the outer boundaries for two polities, as long as the shortest distance is less than 950 kilometers.

Control Variables: ${ }^{18}$ Although our theory predicts that the size of the counter-lobby will reduce the amount of domestic lobbying by an organization (point iii above), it suggests the effects on transnational involvement are indeterminate. Nevertheless, the theory leads us to expect some effect, so it is important to control for this possibility. A number of factors may be cited that could increase the power of the counter lobby. For instance it is likely to go up as the number of domestic veto-players increase, because this increases the chances that one veto will be opposed to further domestic legislation, increasing its price. However, specifically we contend that the domestic fossil-fuel production industry is likely to be opposed. Hence our measure of the size of the counter-lobby against extending national policy is fossil fuel production - a country's oil, gas, and coal production per capita, measured in millions of tons of oil equivalent for 1990-2005 (Bättig and Bernauer 2009). For each dyad, we take the lower of the national values.

\footnotetext{
${ }^{17}$ A gravity model specifies that dyadic trade increases with the size of each economy and decreases with the distance between them. For an application to international conflict see Hegre, Oneal and Russett (2010). Results do not change between using the actual bilateral trade and the imputed trade proxy variable.
}

${ }^{18}$ Unless we note another source, data are from the World Bank Development Indicators. 
In order to control for the effect of trade openness, we create trade share - the share of total trade in GDP, based on trade proxy variable, for the dyad member with the smallest share. We use two variables to control for a country's environmental conditions: $C C I$ is the climate vulnerability index (Guillaumont and Simonet 2011) and CO2 pc is CO2 emissions per capita. Similarly, we follow the weakest link approach to create the dyadic version of the variables.

Because many TCGs surround carbon trading, it is important to control for the size of a country's financial sector, as some financial organizations may have an interest. However, it is quite difficult to find a convincing proxy. Because of wider data availability, ultimately we used bank deposits per GDP - bank deposits normalized by GDP for the dyad member with the smallest financial sector. ${ }^{19}$ Because the corporate sector's interest in environmental issues may affect a country's TCG involvement, we control for the number of ISO14001 certificates normalized by the size of GDP. As suggested by Andonova, Hale and Roger's study (2014) we include measures of democracy and decentralization: polity is the democracy score of the country with the lower level democracy within a dyad on the 21-point Polity IV scale (Marshall, Jaggers and Gurr 2011); federation is a federalism dummy variable indicating whether both countries are federal states. EU is a dummy variable which takes the value 1 if both countries are EU member states. Finally, we also control for the effects of real GDP per capita and population size, also following the weakest link approach. Wealth is often associated environmental values, therefore increasing the level of environmental demand from the citizens, part of which might be

\footnotetext{
${ }^{19}$ The bank deposit variable might be problematic because, for instance, not all financial institutions are involved in carbon trading.
} 
translated into transnational actions. A large country, by its sheer size of the economy and connections with other countries, might have a higher chance of forming TCG ties. ${ }^{20}$

\section{Latent Space Model}

Justification: The dependent variable of this study belongs to the relational ("dyadic") data-type, which consists of measurements that are made on pairs of objects or under pairs of conditions. Statistical modelling of relational data often poses a challenge to standard statistical models which assume independence among observations. Inter-dependencies among dyadic observations are prevalent in most relational data (Wasserman and Faust 1994; Hoff, Raftery, and Handcock 2002). This concern is relevant for this study because of the possibility of autocorrelation among dyadic observations of the dependent variable: the shared numbers of transnational arrangements are likely to be highly correlated between dyads of countries. For example, if Germany shares many ties with France, and France shares many with Italy, it is very likely that Germany shares a large number of ties with Italy (unless the ties shared between Germany and France and the ties shared between France and Italy do not overlap). This kind of autocorrelation between dyadic observations is often called "third-order dependence" in the statistical literature. Ignoring thirdorder dependence in dyadic data and treating dyads Germany-France, France-Italy, and Germany-Italy as independent observations can cause bias in parameter estimates (Hoff 2005).

\footnotetext{
${ }^{20}$ We provide a detailed discussion of the effects of control variables in the online appendix.
} 
The statistical literature has proposed a series of latent space to control for autocorrelation among dyadic observations (Hoff, Raftery, and Handcock 2002; Hoff 2005). Countries' unobserved characteristics are captured by latent vectors: e.g., we can use two latent vectors, $z_{i}$ and $z_{j}$, to locate countries in $i$ and $j$ in the latent space, capturing third-order dependence (autocorrelation) in the dyadic observations of transnational ties among them. The latent space model has recently been applied in the political science literature, but it has mainly been used to model actual flows such as trade and migration (Ward and Hoff 2007; Breunig, Cao, and Luedtke 2012; Cao and Ward 2014). In this study, we use the following latent space model:

$\mathrm{y}_{\mathrm{i}, \mathrm{j}}=\beta_{\mathrm{d}}^{\prime} x_{i, j}+a_{i}+b_{j}+\epsilon_{i, j}+z_{i}^{\prime} z_{j}$

where $\mathrm{y}_{\mathrm{i}, \mathrm{j}}$ is the number of transnational ties between country $i$ and $j,{ }^{21} \beta_{\mathrm{d}}^{\prime} x_{i, j}$ represents covariates (e.g., domestic legislation, green NGOs, size of domestic energy sector, and dyadic trade volume), and $a_{i}$ and $b_{j}$ the country random effects. $\epsilon_{i, j}$ is a normally distributed random error. Therefore, without the cross product of latent vectors $\left(z_{i}^{\prime} z_{j}\right), \mathrm{y}_{\mathrm{i}, \mathrm{j}}=\beta_{\mathrm{d}}^{\prime} x_{i, j}+a_{i}+b_{j}+\epsilon_{i, j}$ is a typical random effects regression setup with a dyadic dependent variable.

The cross product of latent vectors of $i$ and $j---z_{i}^{\prime} z_{j}$ are added to control for third-order dependence/autocorrelation in dyadic observations of the dependent variable $\left(\mathrm{y}_{\mathrm{i}, \mathrm{j}}{ }^{\prime} \mathrm{s}\right){ }^{22}$ Note that

${ }^{21}$ We use a Poisson link function.

22 The dimensionality of the latent vectors can be chosen depending on the purpose of the model: if the goal is descriptive, then a choice of $\mathrm{k}=1,2$ or 3 would allow for a simple graphical 
we have not exhausted all potentially relevant variables (for example, common culture between two countries). However, the latent space model controls for these by country random effects $\left(a_{i}\right.$ and $\left.b_{j}\right)$ and the cross-product of countries' latent positions $\left(z_{i}^{\prime} z_{j}\right)$. The former $\left(a_{i}\right.$ and $\left.b_{j}\right)$ control for domestic variables and the latter $\left(z_{i}^{\prime} z_{j}\right)$ can be considered as taking up the unexplained interactive/dyadic effects. ${ }^{23}$

Empirical Results: Table 1 summarizes the posterior distributions of the effects of covariates and the variances of country random effects, random error, and the three latent dimensions. We include density plots to show the $95 \%$ confidence intervals (by blue vertical lines) in Figure 6 . We are first of all interested in whether the four variables implied by our theories affect chances of TCG ties between countries. We italicize these four variables in Table 1: Trade proxy, Distance, Domestic legislation, and Green NGOs. Specifically, Table 1 shows the lower and upper bounds of the $95 \%$ confidence intervals, the mean, and the standard deviation of the

presentation; alternatively, one could examine model fit as a function of $\mathrm{k}$ based on the loglikelihood, or use a cross-validation criterion if one is primarily concerned with predictive performance. See Hoff 2005. The goal for this paper is to control for higher-order dependencies. Log-likelihoods suggest that model fits better when $\mathrm{k}=2$ or 3 ; to be consistent, we set $\mathrm{k}=3$. Results when setting $\mathrm{k}=2$ are in the second model specification of Table $\mathrm{A} 2$ of the online appendix.

${ }^{23}$ The latent positions and the latent space model are estimated by Bayesian Markov chain Monte Carlo. Empirical Bayes priors are used. 
posterior distributions. Here, we find no evidence that the level of bilateral trade affects TCG participation (H4 is not suported). The distance between countries also has no effect on their shared TCGs (H3 is not supported). These two non-results seem to suggest that transaction costs for organizations to deal with organizations outside its national base hardly affects their TCG efforts.

(Table 1 here)

On the other hand, we find domestic legislations and domestic green NGOs are both positively associated with shared TCGs between countries (H1 and $\mathrm{H} 2$ are supported). This confirms our central theoretical claim that TCG links between two countries increase with the level of development of national policy, and our subsidiary claim that the strength of domestic support constituency for international action matters. In terms of the substantive effects, holding all variables at their mean levels, the mean predicted TCG between any two countries is about 0.75 (mean of a Poisson distribution); if we increase the value of the domestic legislation variable by one standard deviation, that is, from a mean of 2.03 to about 4.29 , the mean predicted betweencountry TCGs increases by about $5.5 \%$ (to 0.79 ); moreover, a two standard deviation increase in the domestic legislation variable increases the mean predicted between-country TCGs by about $11 \%$. The substantive effect of the domestic green NGOs variable is smaller but still not 
negligible: here a one standard deviation increase from the mean increases the mean predicted TCGs by about $3.4 \%$ and a two standard deviation increase by about $7 \%{ }^{24}$

(Figure 6 and Table 2 here)

In addition to the aforementioned four variables, we include a number of controls. Looking at Table 1 and Figure 6, few of them matter for TCG connections between countries. However, we do find that countries with higher level of trade to GDP share (trade openness) are associated with more links, suggesting that countries that are more open economically also have organizations more proactive in relation to building transnational climate governance. Moreover, we also find that real GDP per capita matters as wealthier countries are associated with higher number of links.

The size of the counter lobby is of particular interest because our theory suggests that it should matter, although the direction of the relationship is not predicted. Looking at both Table 1 and Figure 6, we also see no evidence that the size of domestic counter lobby, measured by a

${ }^{24}$ Our predicted substantive effects are calculated only using covariates, that is, $\beta_{\mathrm{d}}^{\prime} \mathrm{x}_{\mathrm{i}, \mathrm{j}}$ in $y_{i, j}=\beta_{d}^{\prime} x_{i, j}+a_{i}+b_{j}+\epsilon_{i, j}+z_{i}^{\prime} z_{j} ;$ a careful reading of Table 1 suggests that there is significant amount of variance not explained by the covariates $\left(\beta_{\mathrm{d}}^{\prime} \mathrm{x}_{\mathrm{i}, \mathrm{j}}\right)$; actually the variance of country Random Effects $\left(\sigma_{\mathrm{a}}^{2}\right)$ is relatively large with the estimated mean around 4.28, suggesting country random effects $\left(a_{i}+b_{j}\right)$ explain quite a significant amount of variation in the DV. 
country's oil, gas, and coal production per capita, affects the number of TCGs shared by two countries. In order to assess robustness, we also use another indicator: fossil fuel energy consumption a percentage of total energy consumption. The results are presented among robustness checks in Table 2. Table 2 shows the lower and upper bounds of both the $90 \%$ and 95\% confidence intervals. Here, we also find no association between the importance of fossil fuel energy consumption and TCG network links.

Insitutional constraints at the domestic level may inhibit both domestic and transnational action; so as a robustness check we add Henisz' (2002) widely-used measure of domestic veto players. ${ }^{25}$ We substitute a specific measure of civil liberties for our more general measure of democracy (polity), as freedom of expression and association may be more crucial for the green lobby than free elections in which green parties have little success. ${ }^{26}$ Interestingly, we find neither of these variables affects TCGs links, even at lower levels of significance. In Table 2, H1 is still supported, but we do find that the green NGO variable is now only significant at the $90 \%$ level; so support for $\mathrm{H} 2$ is somewhat weaker.

\footnotetext{
${ }^{25}$ We use the country scores averaged over the 1990 and 2004 period.

${ }^{26}$ Civil liberties allow for the freedoms of expression and belief, associational and organizational rights, rule of law, and personal autonomy without interference from the state. Data are provided by the Freedom House. Countries are graded between 1 (most free) and 7 (least free). We used the country scores averaged over 1990-2008.
} 


\section{Conclusions}

Our theory suggests that, dependent on characteristics of the weakest link in the dyad, the number of network ties between two countries should increase with domestic legislation (H1), the number of domestic environmental NGOs (H2), and the density of trade between the two countries (H4). It should decrease with the distance between the two countries (H3). We find that H1 and (somewhat more weakly) H2 are supported. Few other domestic covariates are significant, though ties are greater if the weakest link is richer and a more open economy. Neither vulnerability to climate change nor $\mathrm{CO} 2$ production per-capita matters, so ties appear not to be driven by the seriousness of climate change as an issue for the weakest link. While ties appear to be promoted by a powerful domestic green lobby (H2), there is no evidence that a bigger financial sector (that might benefit from carbon trading) or more firms adopting voluntary environmental management standards matter. Moreover, there is no evidence that the size of the carbon counter-lobby matters. While it is gratifying that we find the anticipated effects of domestic legislation using a more direct indicator, there is clearly considerably more work to do in developing theory.

Our approach could be developed in a number of ways. We highlight that involvement in TCG is linked with the ability to exert pressure, so that domestic lobbying relates to international governance. Because of this, domestic institutional variables found to be important in the comparative political economy literature should relate to TCG: majoritarian versus proportional representation; presidential versus parliamentary; and the nature of the party system (Persson and Tabellini 2005) or corporatism (Scruggs 2003). We argue that transnational ties do more than 
link the organizations directly involved. They are conduits through which information can flow between countries, linking organisations not directly involved in TCG. As such, they present the possibility of diffusion of policy and learning. In further research the TCG network discussed in this paper could be used to study policy diffusion by employing the spatial lag methods that have recently found application in the international environmental politics literature (Ward and Cao 2012). Another question suggested by our emphasis on the relation between TCG and domestic politics is whether domestic policy outputs are made more effective in terms of their impact on carbon-emissions by involvement in TCG networks. For instance does centrality in the TCG network condition effectiveness?

We find ties are strongest between rich countries and between rich countries and some NICs (Bulkeley et al. 2014:117-133). In relation to rich countries, ties are denser between countries with developed national climate change legislation and strong environmental movements. If it turns out the network does promote information transfer and diffusion, on the one hand it tends most strongly to link countries most responsible for greenhouse gas emissions. On the other it may not function so well to link developed countries and poorer ones which are peripheral to the network. In other words, the current network structure of the global TCG network might not help the information flows between the rich and poor countries as much as we would like to see.

While recognizing the role that states can play in forging governance arrangements over climate change, the literature sees governance by non-state actors as an important complement to international regimes and state-led governance networks. Flexibility mechanisms under the 
Kyoto Protocol encourage the involvement of a range of non-state actors; and the weakness of the regime encourages the formation of 'coalitions of the willing' from 'outside' the regime (Andonova, Betsill and Bulkeley 2007:4). On the other hand there are serious concerns about weak governance of carbon markets that have emerged under the Kyoto Protocol (Newell and Paterson 2010:141-160) and about the need to develop new accountability mechanisms (Keohane 2006). Different forms of accountability mechanisms (Bäckstrand 2008) and different bases of legitimacy (Bulkeley et al. 2014:134-157) may be appropriate for different sorts of TCG arrangements; and some accountability mechanisms could involve corporations or governments, rather than civil society or citizens as a whole. However, Lidskog and Elander (2010) argue that addressing climate change in a democratic and efficient manner requires greater integration between the climate change regime, built by states, and TCG. We suggest this implies greater grass-roots and citizen involvement. De Búrca, Keohane and Sabel (2014; see also Stevenson and Dryzek 2012) propose 'global experimentalist governance', which implies continual review of both international and transnational governance through a deliberative and inclusive process reaching down to citizens at grass-roots level, facilitating learning and reflection on the overall process of governance. In such a conception, adequate flows of information are crucial: otherwise, justification of practices through deliberation cannot function in a satisfactory manner. When a country is peripheral to the network we focus on, its government and citizens will receive relatively little information compared to those from a country central to the network. From this perspective transnational climate change governance is not open enough to deliberative justification - and it is certainly not open enough to justification to poor citizens in poor countries. The emergent network we study tends to exclude poor countries and, because of 
this, TCG is less shaped by the preferences of their citizens. Therefore TCG may be less responsive to the very people who are most likely to suffer the negative consequences of climate change.

\section{REFERENCES}

Abbott, Kenneth W. (2012) The transnational regime complex for climate change. Environment and Planning C: Government and Policy 30(4):571 - 590.

Andonova, Liliana B. (2014) Boomerangs to Partnerships? Explaining State Participation in Transnational Partnerships for Sustainability. Comparative Political Studies 47(3):481-515.

Andonova, Liliana B., Michele M. Betsill, and Harriet Bulkeley. (2007) Transnational Climate Change Governance. Paper Presented at the Amsterdam Conference on the Human Dimensions of Global Environmental Change, Amsterdam, May 24-26.

Andonova, Liliana B., Michele M. Betsill, and Harriet Bulkeley. (2009) Transnational Climate Governance. Global Environmental Politics 9(2):52-73.

Andonova, Liliana B., Thomas Hale, and Charles Roger. (2014) How Do Domestic Politics Condition Participation in Transnational Climate Governance? Paper Presented at the Political Economy of International Organizations Conference, Princeton, NJ, January 16-18.

Bäckstrand, Karin. (2008) Accountability of Networked Climate Governance: The Rise of Transnational Climate Partnerships. Global Environmental Politics 8(3):74-102. 
Bättig, Michèle B. and Thomas Bernauer. (2009) National Institutions and Global Public Goods: Are Democracies More Cooperative in Climate Change Policy? International Organization 63 (2):281-308.

Baumgartner Frank, R. and Bryan D. Jones. (1993) Agendas and Instability in American Politics, Chicago: University of Chicago Press.

Bechtel, Michael M., and Johannes Urpelainen. (2015) All Policies Are Glocal: International Environmental Policy Making with Strategic Subnational Governments. British Journal of Political Science 45 (03):559-582.

Bernauer, Thomas, Tobias Böhmelt, and Vally Koubi. (2013) Is There a Democracy-Civil Society Paradox in Global Environmental Governance? Global Environmental Politics 13(1):88107.

Besley, Tim, and Anne Case. (1995) Incumbent Behavior: Vote Seeking, Tax Setting and Yardstick Competition. American Economic Review 85(1):25-45.

Böhmelt, Tobias and Jürg Vollenweider. (2015) Information Flows and Social Capital Through Linkages: The Effectiveness of the CLRTAP Network. International Environmental Agreements $15(2): 105-123$.

Breunig, Christian, Xun Cao, and Adam Luedtke. (2012) Global Migration and Political Regime Type: A Democratic Disadvantage. British Journal of Political Science 42(4):825-854.

Bulkeley, Harriet. (2010) Cities and the Governing of Climate Change. Annual Review of Environment and Resources 35:229-254. 
Bulkeley, Harriet, Liliana B. Andonova, Michele M. Betsill, Thomas Hale, Matthew J. Hoffmann, Peter Newell, Matthew Paterson, Charles Roger and Stacy D. Vandeveer . (2014) Transnational Climate Governance. Cambridge: Cambridge University Press.

Cao, Xun and Michael D. Ward. (2014) Do Democracies Attract Portfolio Investment? International Interactions 40(2):216-245.

Xun Cao and Aseem Prakash. (2010) Trade Competition and Domestic Pollution: A Panel Study, 1980-2003. International Organization 64(3):481-503.

Xun Cao and Aseem Prakash. (2012) Trade Competition and Environmental Regulations: Domestic Political Constraints and Issue Visibility. Journal of Politics 74(1):66-82.

Cranmer, Skyler J. and Bruce A. Desmarais. (2011) Inferential Network Analysis with Exponential Random Graph Models. Political Analysis 19(1):66-86.

De Búrca, Gráinne, Robert O. Keohane and Charles Sabel. (2014) Global Experimentalist Governance. British Journal of Political Science 44(3):477 - 486.

Dorussen, Han and Hugh Ward. (2010) Trade Links and the Kantian Peace: A NetworkTheoretic Approach to Communication, Inter-Cultural Understanding, and Conflict. Journal of Peace Research 47(1):29-42.

Dixon, William J. (1993) Democracy and the Management of International Conflict. Journal of Conflict Resolution 37(1):42-68.

Dolšak, Nives and Aseem Prakash. (2017) Join the Club: How Domestic NGOs Induce Participation in the Covenant of Mayors Program. International Interactions. 
Edwards, Bob and John D. McCarthy. (2004) Resources and Social Movement Mobilization. In The Blackwell Companion to Social Movements, edited by David A. Snow, Sarah A. Soule, and Hanspeter Kriesi. Oxford: Blackwell.

Green, Jessica. F. (2013) Order out of Chaos: Public and Private Rules for Managing Carbon. Global Environmental Politics 13(2):1-25.

Green, Jessica F (2014) Rethinking Private Authority: Agents and Entrepreneurs in Global Environmental Governance. Princeton: Princeton University Press.

Green, Jessica F. (2017) Blurred Lines: Why do states recognize private carbon standards? International Interactions

Grundig, Frank and Hugh Ward. (2015) Structural Group Leadership and Regime Effectiveness. Political Studies 63(1):221-239.

Guillaumont, Patrick and Catherine Simonet. (2011) Data from "Building an Index of Physical Vulnerability to Climate Change’. Fondation pour les études et recherches sur le développement international.

Hale, Thomas and Charles Roger. (2014) Orchestration and Transnational Climate Governance. Review of International Organizations 9(1):59-82.

Hafner-Burton, Emilie M., Miles Kahler, and Alexander H. Montgomery. (2009) Network Analysis for International Relations. International Organization 63(3):559-592. 
Hegre, Håvard, John R. Oneal and Bruce Russett. (2010) Trade Does Promote Peace: New Simultaneous Estimates of the Reciprocal Effects of Trade and Conflict. Journal of Peace Research 47(6):763-774.

Henisz, Witold J. (2002) The Institutional Environment for Infrastructure Investment. Industrial and Corporate Change 11(2):355-389.

Hirshleifer, Jack. (1983) From Weakest-Link to Best-Shot: The Voluntary Provision of Public Goods. Public Choice 41(3):371-386.

Hoff, Peter D. (2005) Bilinear Mixed Effects Models for Dyadic Data. Journal of the American Statistical Association 100(2):286-295.

Hoff, Peter D., Adrian E. Raftery, and Mark S. Handcock. (2002) Latent Space Approaches to Social Network Analysis. Journal of the American Statistical Association 97(469):1090-1098.

Hoff, Peter D. and Michael D. Ward. (2004) Modelling Dependencies in International Relations Networks. Political Analysis 12(2):160-175.

Holzinger, Katharina, Christoph Knill and Thomas Sommerer. (2008) Environmental Policy Convergence: The Impact of International Harmonization, Transnational Communication, and Regulatory Competition. International Organization 62(4):553-587.

Hsueh, Lily. (2017)Who sets the agenda in global climate change? Explaining private actor participation by internal firm-level factors and dynamics. International Interactions.

Jones, Bryan D. and Frank R. Baumgartner. (2005) The Politics of Attention: How Government Prioritizes Problems. Chicago: University of Chicago Press 
Kalbhenn, Anna. (2011) Liberal Peace and Shared Resources - A Fair-Weather Phenomenon? Journal of Peace Research 48(6):715-735.

Keck, Margaret E. and Kathryn Sikkink. (1998) Activists Beyond Borders: Advocacy Networks in International Politics. Ithaca, Cornell University Press.

Keohane, Robert O. (2006) Accountability in World Politics. Scandinavian Political Studies 29(2):75-87.

Keohane, Robert O, and David G. Victor. (2011) The Regime Complex for Climate Change. Perspectives on Politics 9(1):7-23.

Lee, Taedong and Susan van de Meene. (2012) Who Teaches and Who Learns? Policy Learning through the C40 Cities Climate Network. Policy Sciences 45(3):199-220.

Lidskog, Rolf and Ingemar Elander. (2010) Addressing Climate Change Democratically. MultiLevel Governance, Transnational Networks and Governmental Structures. Sustainable Development 18(1):32-41.

Marshall, Monty G., Keith Jaggers \& Ted Robert Gurr. (2011) Polity IV Project: Dataset Users' Manual. Center for Systemic Peace: Polity IV Project.

Newell, Peter and Matthew Paterson. (2010) Climate Capitalism: Global Warming and the Transformation of the Global Economy. Cambridge: Cambridge University Press.

Ostrom, Elinor. (2012) Nested Externalities and Polycentric Institutions: Must We Wait For Global Solutions to Climate Change Before Taking Actions at Other Scales? Economic Theory 49(2):353-369. 
Oneal, John R. and Bruce Russett. (1997) The Classical Liberals were Right. International Studies Quarterly 41 (4):267-293.

Persson, Torsten and Guido Tabellini. (2005) The Economic Effects of Constitutions. Cambridge: MIT Press.

Potoski, Matthew and Aseem Prakash. (2005) Green Clubs and Voluntary Governance: ISO 14001 and Firms' Regulatory Compliance. American Journal of Political Science 49(2):235248.

Prakash, Aseem and Mary Kay Gugerty. (2010) Advocacy Organizations and Collective Action: An Introduction. In Advocacy Organizations and Collective Action, edited by Assem. Prakash and Mary Kay Gugerty. New York: Cambridge University Press.

Roger, Charles, Thomas Hale, and Liliana B. Andonova. (2017) Domestic Politics and Climate Governance. International Interactions.

Schaffer, Lena M. and Thomas Bernauer. (2014) Explaining the Adoption of Renewable Energy Policies. Energy Policy 68:15-27.

Scruggs, Lyle. (2003) Sustaining Abundance: Environmental Performance in Industrial Democracies. Cambridge: Cambridge University Press.

Schäferhoff, Marco, Sabine Campe, and Christopher Kaan. (2009) Transnational Public-Private Partnerships in International Relations: Making Sense of Concepts, Research Frameworks, and Results. International Studies Review 11(4):451-474. 
Simmons, Beth, Frank Dobbin, and Geoffrey Garrett. (2006) Introduction: The International Diffusion of Liberalism. International Organization 60(4):781-810.

Spilker, Gabriele. (2012) Helpful Organizations: Membership in Inter-Governmental Organizations and Environmental Quality in Developing Countries. British Journal of Political Science 42(2):345-370.

Stevenson, Hayley and John S. Dryzek. (2012) The Discursive Democratisation of Global Climate Governance. Environmental Politics 21(2):189-210.

Vogel, David. (1995) Trading Up: Consumer and Environmental Regulation in a Global Economy. Cambridge: Harvard University Press.

Ward, Hugh. (2006) International Linkage and Environmental Sustainability: The Effectiveness of the Regime Network. Journal of Peace Research 43(2):149-166.

Ward, Hugh and Xun Cao. (2012) Domestic and International Influences on Green Taxation. Comparative Political Studies 45(4):1075-1103.

Ward, Michael D., and Peter D. Hoff. (2007) Persistent Patterns of International Commerce. Journal of Peace Research 44(2):157-175.

Ward, Michael D., Katherine Stovel, and Audrey Sacks. (2011) Network Analysis and Political Science. Annual Review of Political Science 14:245-264.

Wasserman, Stanley and Katherine. Faust. (1994) Social Network Analysis: Methods and Applications. Cambridge: Cambridge University Press. 
Widerberg, Oscar. (2014) Mapping Institutions and Actors in Global Climate Governance: A Network Approach. Working Paper. Institute for Environmental Studies (IVM), VU University Amsterdam.

World Economic Forum. (2009) Slimcity: A Cross-Industry, Public-Private Initiative on Urban Sustainability. Available at http://www.weforum.org/pdf/ip/ec/SlimCity.pdf. 
Table 1: summary of posterior distribution: the effects of covariates, error structures, and latent dimensions.

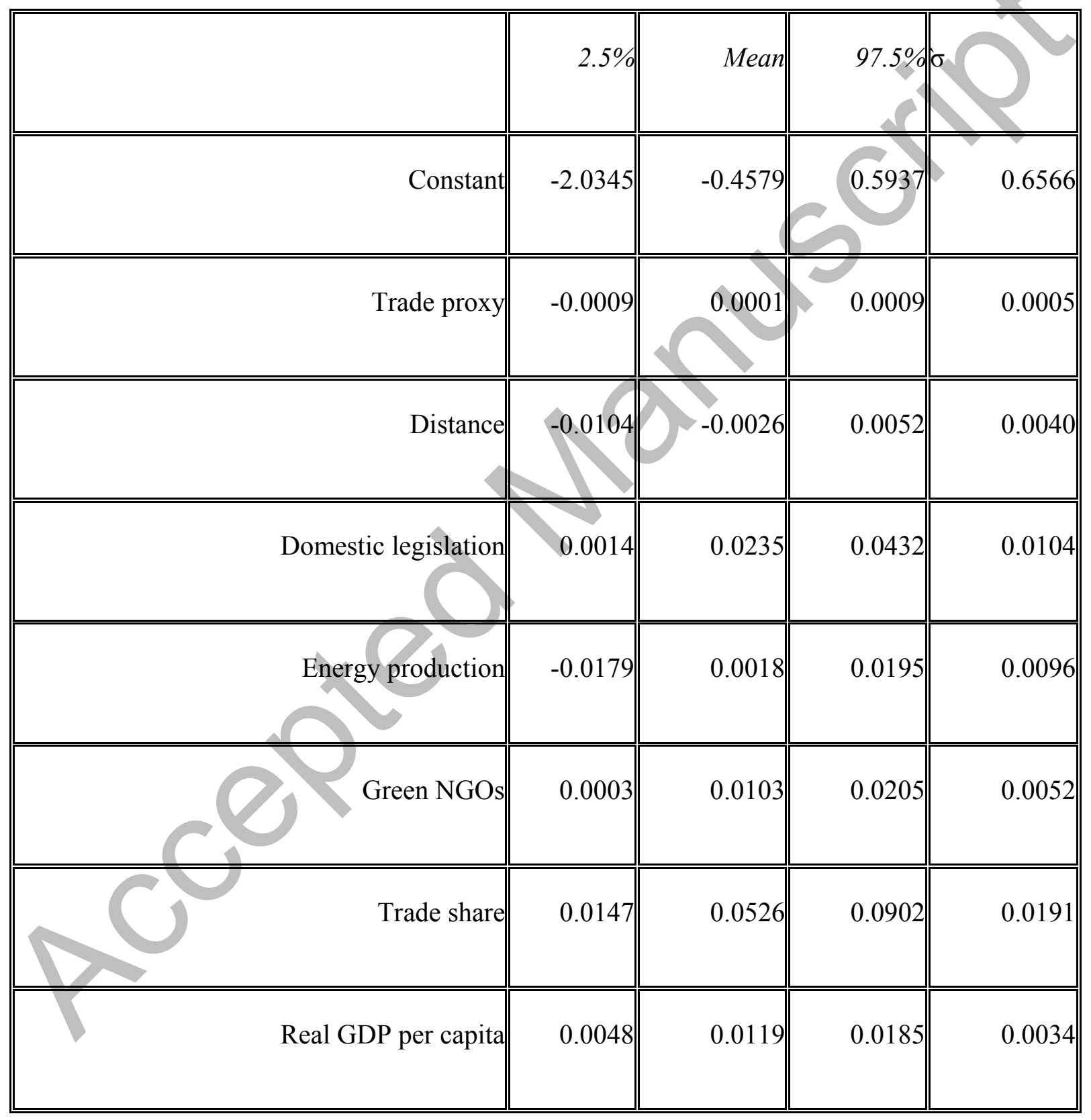




\begin{tabular}{|c|c|c|c|c|}
\hline Polity & -0.0184 & 0.0040 & 0.0245 & 0.0109 \\
\hline $\mathrm{CCI}$ & $-1.0621 \|$ & -0.1742 & 0.7523 & 0.4591 \\
\hline $\mathrm{CO} 2 \mathrm{pc}$ & -0.0123 & 0.0097 & 0.0319 & 0.0116 \\
\hline EU & -0.0640 & 0.1333 & 0.3225 & 0.0963 \\
\hline Bank deposits per GDP & -0.1698 & 0.0406 & 0.2482 & 0.1078 \\
\hline Federation & -0.0212 & 0.1235 & 0.2641 & 0.0732 \\
\hline Population & $-0.0001 \|$ & 0.0002 & 0.0005 & 0.0002 \\
\hline ISO14000 per GDP & -0.0127 & 0.0137 & 0.0381 & 0.0134 \\
\hline Variance of Country Random Effects $\left(\sigma_{a}^{2}\right)$ & 1.5067 & 4.2789 & 11.6405 & 3.0839 \\
\hline Error Variance $\left(\sigma_{\gamma}^{2}\right)$ & 0.0059 & 0.0083 & 0.0112 & 0.0013 \\
\hline
\end{tabular}




\begin{tabular}{||l||r|r||r||r||}
\hline Variance of Latent Dimensions $1\left(\sigma_{z 1}^{2}\right)$ & 0.2630 & 0.3914 & 0.5882 & 0.0836 \\
\hline \hline Variance of Latent Dimensions $2\left(\sigma_{z 2}^{2}\right)$ & 0.0228 & 0.0630 & 0.1427 & 0.0329 \\
\hline Variance of Latent Dimensions 3 $\left(\sigma_{z 3}^{2}\right)$ & 0.0188 & 0.0405 & 0.0977 & 0.0195 \\
\hline \hline Log Likelihood $(L-L)$ & -2979.10 & -2950.17 & -2918.43 & 15.53 \\
\hline
\end{tabular}


Table 2: Latent space model estimates for shared TCGs: robustness checks.

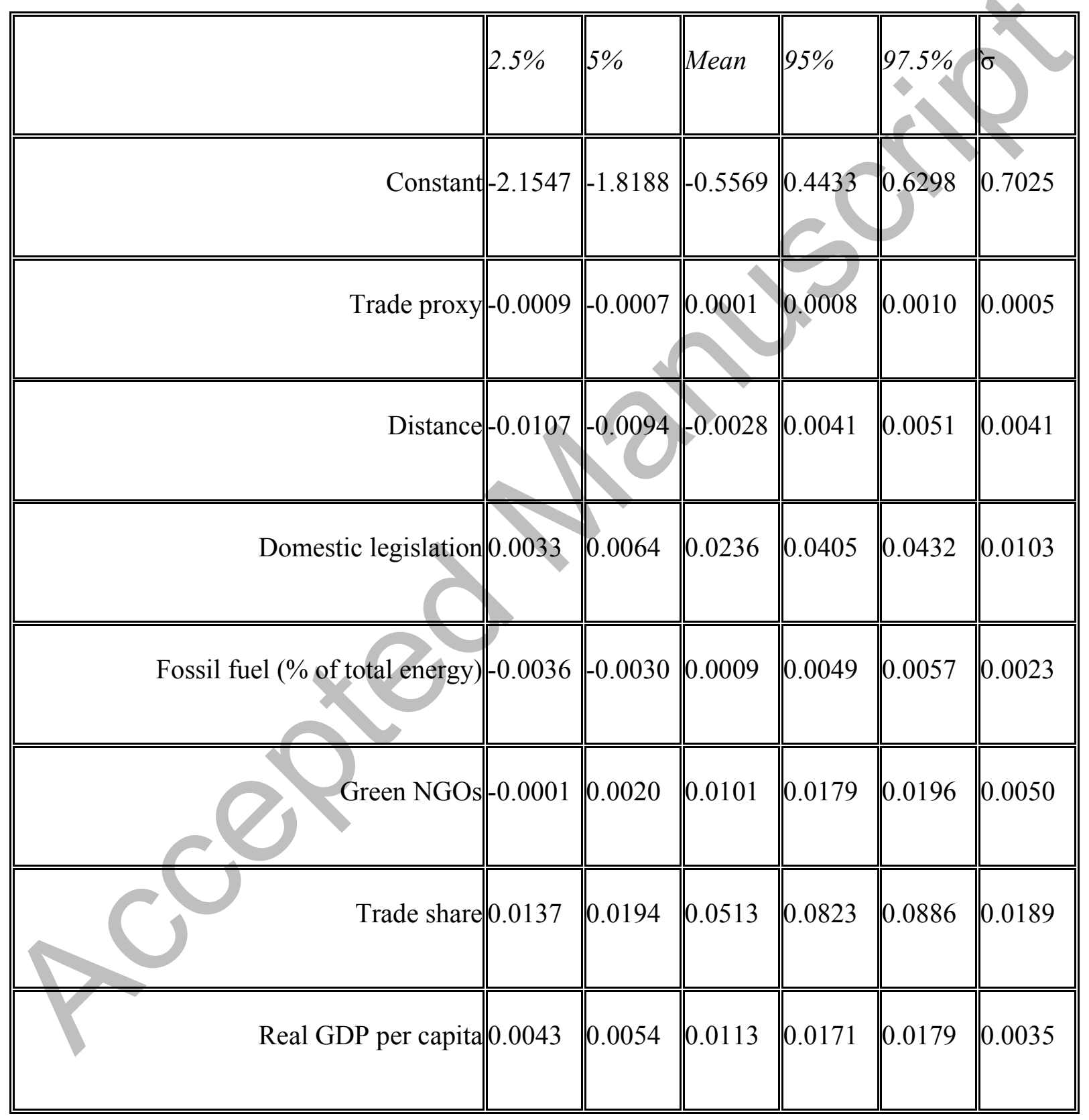




\begin{tabular}{|c|c|c|c|c|c|c|}
\hline Civil liberty & -0.0846 & -0.0697 & -0.0009 & 0.0653 & 0.0792 & 0.0414 \\
\hline Veto player & -0.2676 & -0.1911 & 0.2242 & 0.6015 & 0.6898 & 0.2434 \\
\hline $\mathrm{CCI}$ & -1.0834 & -0.9495 & -0.1877 & 0.5300 & & 0.4525 \\
\hline $\mathrm{CO} 2 \mathrm{pc}$ & -0.0137 & -0.0099 & 0.0087 & 0.0274 & 0.0302 & 0.0114 \\
\hline EU & -0.0587 & -0.0207 & 0.1377 & 0.2894 & 0.3190 & 0.0939 \\
\hline Bank deposits per GDP & -0.1872 & -0.1383 & 0.0386 & 0.2196 & 0.2424 & 0.1101 \\
\hline Federation & -0.0165 & 0.0016 & 0.1185 & 0.2324 & 0.2488 & 0.0714 \\
\hline Population & -0.0001 & -0.0001 & 0.0002 & 0.0005 & 0.0005 & 0.0002 \\
\hline 4000 per GDP & -0.0140 & -0.0087 & 0.0128 & 0.0349 & 0.0399 & 0.0134 \\
\hline Variance of Country Random Effects $\left(\sigma_{a}^{2}\right)$ & 1.5460 & 1.6584 & 4.3811 & 10.7956 & 12.2195 & 3.2100 \\
\hline
\end{tabular}




\begin{tabular}{|c|c|c|c|c|c|c|}
\hline Error Variance $\left(\sigma_{\gamma}^{2}\right)$ & 0.0060 & 0.0062 & 0.0083 & 0.0107 & 0.0113 & 0.0014 \\
\hline Variance of Latent Dimensions $1\left(\sigma_{z 1}^{2}\right)$ & 0.2604 & 0.2771 & 0.3900 & 0.5307 & 0.5663 & 0.0785 \\
\hline Variance of Latent Dimensions $2\left(\sigma_{z 2}^{2}\right)$ & 0.0231 & 0.0256 & 0.0572 & 0.1154 & 0.1317 & 0.0290 \\
\hline Variance of Latent Dimensions $3\left(\sigma_{z 3}^{2}\right)$ & 0.0198 & 0.0220 & 0.0469 & 0.1043 & 0.1227 & 0.0259 \\
\hline Log Likelihood ( & & & & - & - & $\mid 14.89$ \\
\hline & & 2974.14 & 2950.89 & 2924.94 & 2920.96 & \\
\hline
\end{tabular}


Figure 1: The effect of increasing domestic policy on transnational activity.

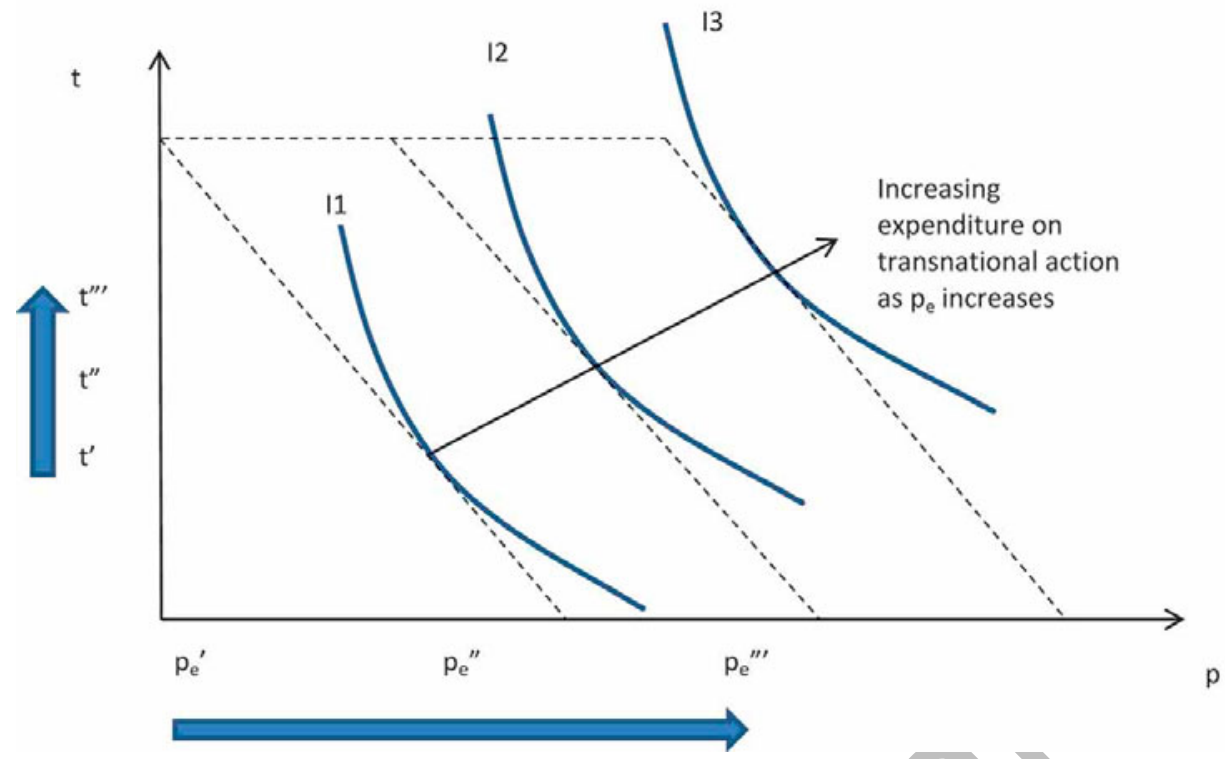


Figure 2: The effect of increasing emphasis on transnational issues in the utility function.
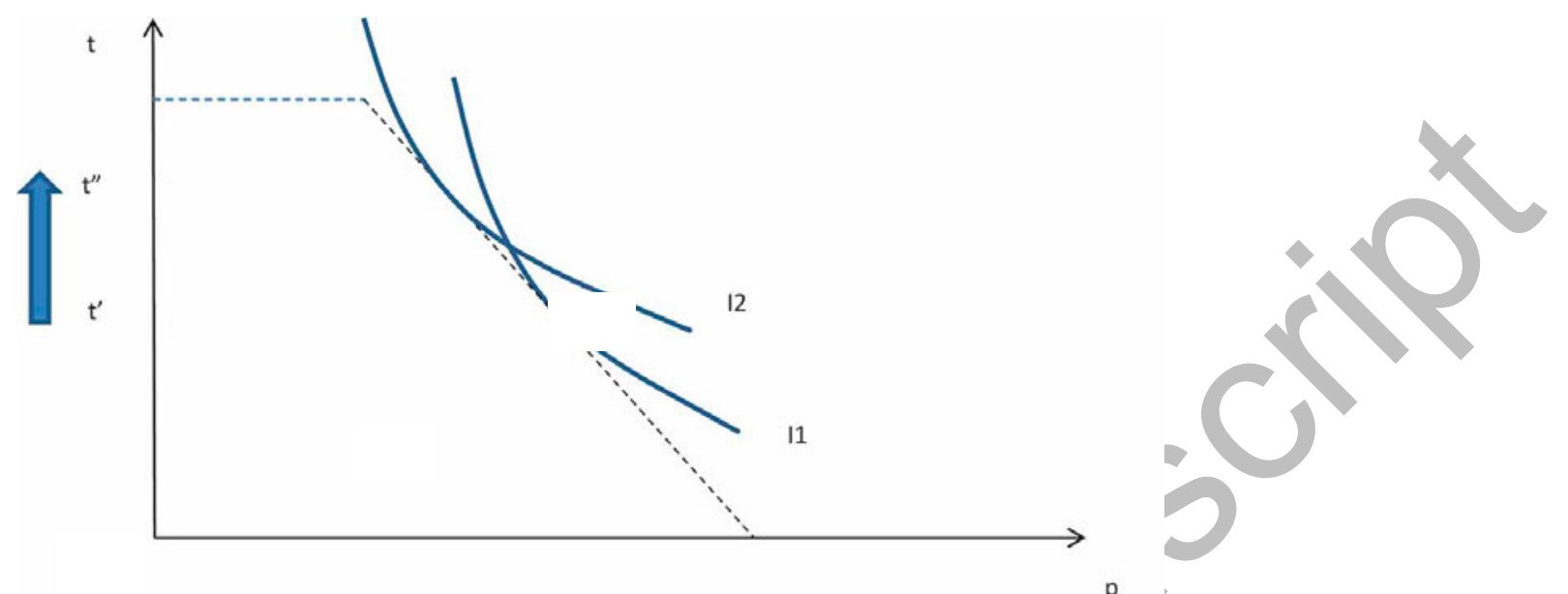
Figure 3: The effect of increasing the price of domestic lobbying.

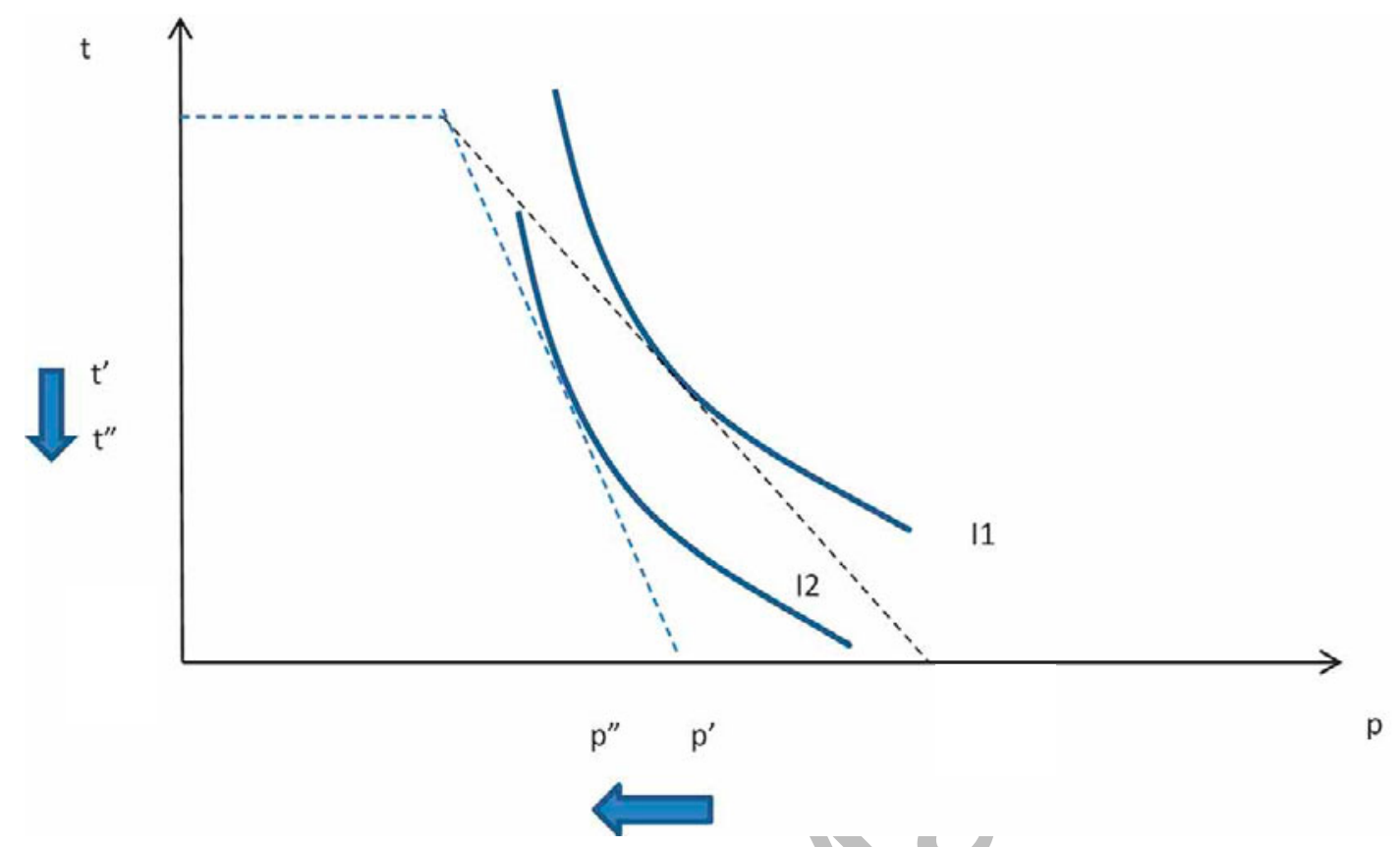


Figure 4: The effect of decreasing the price of transnational action.
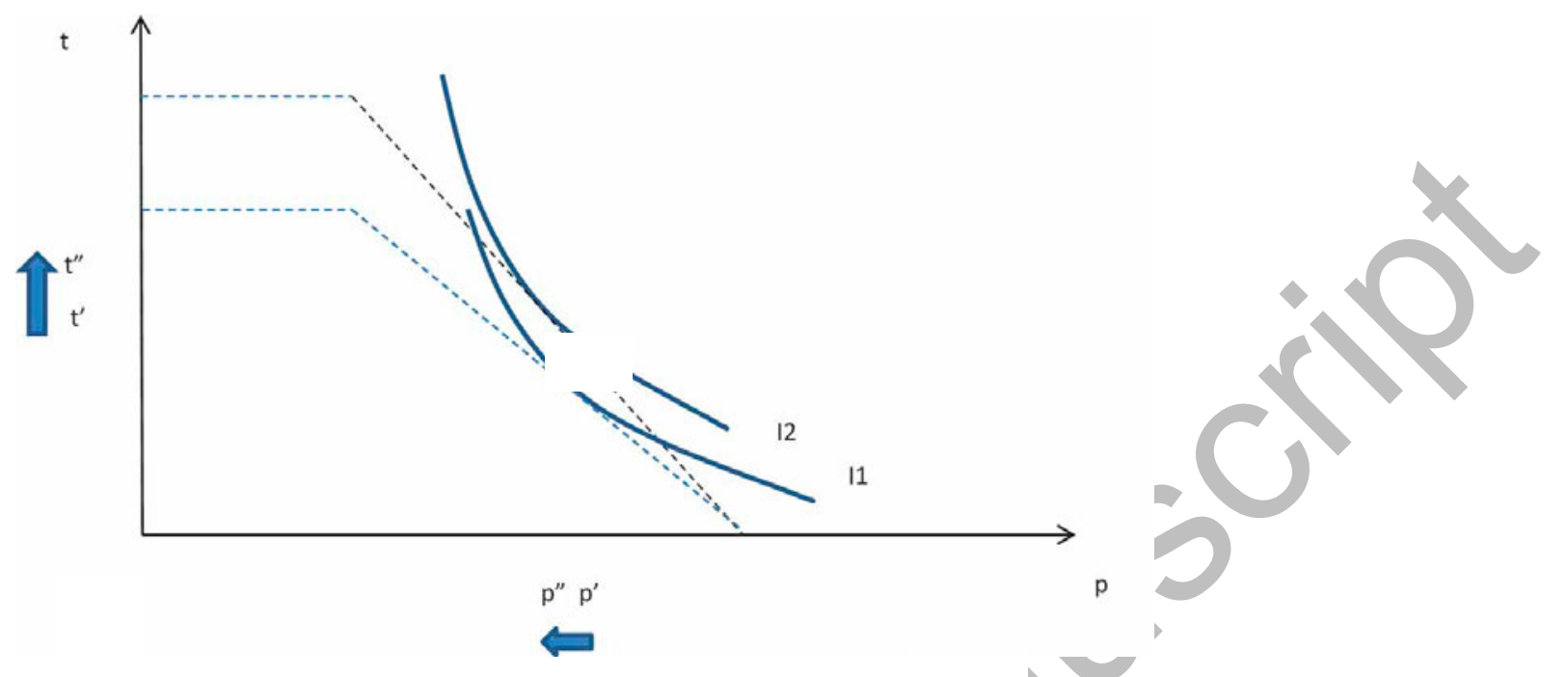
Figure 5: The transnational governance network between countries.

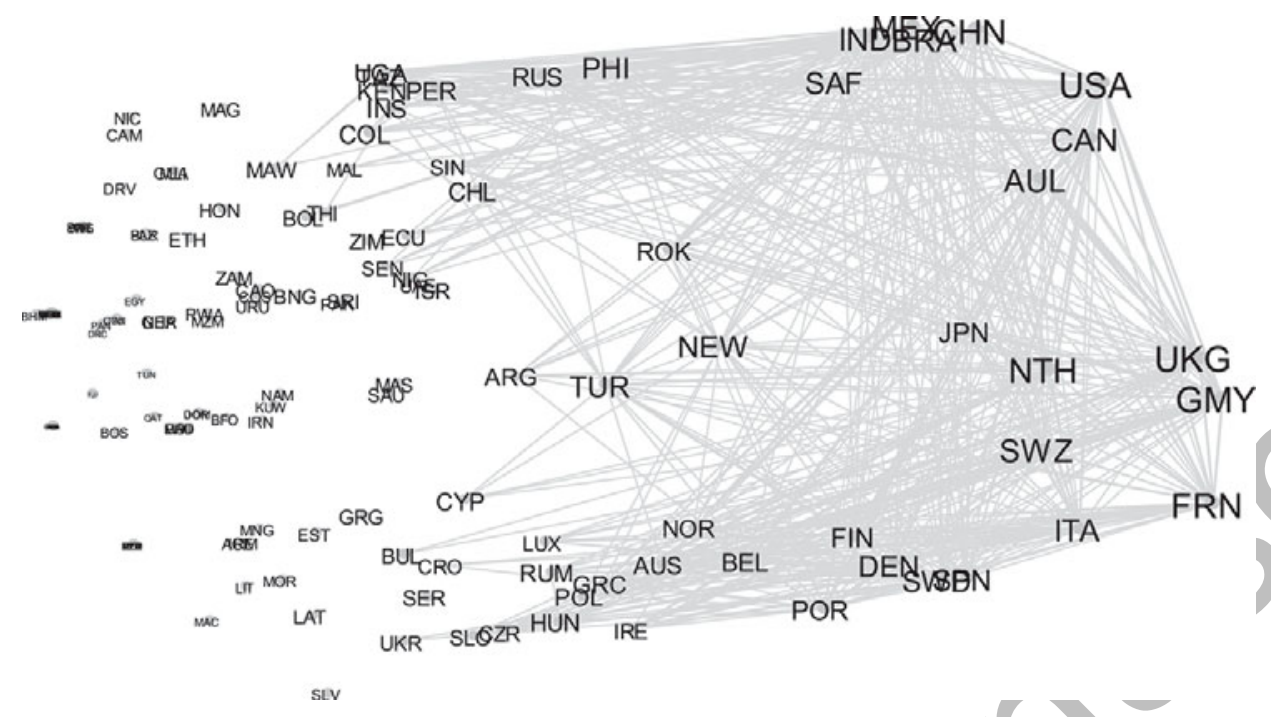


Figure 6: density plots of posterior distributions of the effects of 15 covariates. Note we indicate the $95 \%$ confidence intervals by dashed vertical lines and add solid vertical lines to indicate zeros. One way to evaluate the statistical significance level is whether the $95 \%$ confidence intervals bounded blue vertical lines include zero or not.
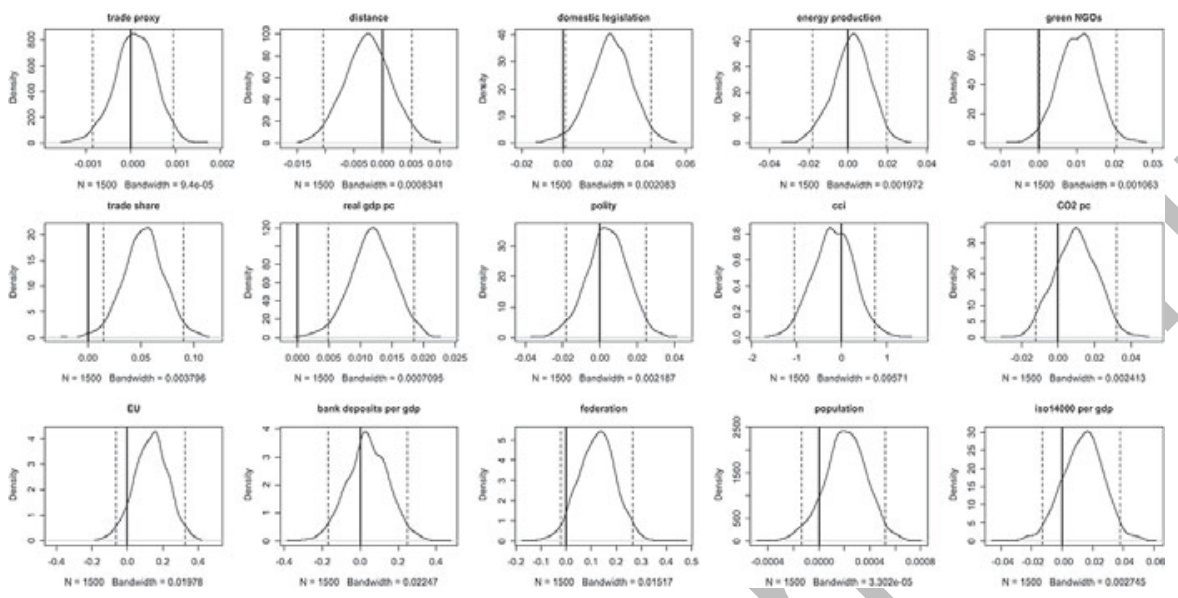